\title{
Dose Rate Effect on Bimetallic Gold-Palladium Cluster Structure
}

\author{
Hynd Remita, Arnaud Etcheberry, ${ }^{\dagger}$ and Jacqueline Belloni* \\ Laboratoire de Chimie Physique, Bât. 349, UMR 8000-CNRS, Université Paris XI, \\ 91400 Orsay Cedex, France, and IREM-Institut Lavoisier, 45 rue des Etats-Unis, UMR 8637-CNRS, \\ Université Versailles Saint-Quentin-en-Yvelines, 78035 Versailles Cedex, France
}

Received: May 22, 2002; In Final Form: October 3, 2002

\begin{abstract}
Radiolytic synthesis of mixed $\mathrm{Au}^{\mathrm{III}} / \mathrm{Pd}^{\mathrm{II}}$ solutions at different dose rates is examined. The evolution of the plasmon spectra and the local X-ray micro diffraction has been systematically studied as a function of irradiation dose and dose rate. At low dose rate, a bilayered cluster of Au core-Pd shell is characterized. Due to intermetal electron transfer from nascent $\mathrm{Pd}$ atoms to gold ions, the latter are reduced first and constitute mainly the core of the particle, $\mathrm{Pd}$ ions being finally reduced at the surface of gold clusters when all $\mathrm{Au}^{\mathrm{III}}$ ions have been reduced. In contrast, at high dose rate when the ion reduction is sudden and faster than a possible inter-metal electron transfer, it is shown by UV-vis spectroscopy, XPS, and EDAX results that genuine alloyed clusters are formed.
\end{abstract}

\section{Introduction}

Multimetallic clusters, particularly when intimately alloyed, are of high interest because of their optical and catalytic properties. ${ }^{1-3}$ Bimetallic clusters were synthesized by numerous methods, but the synthesis of alloyed clusters is much more difficult than that of core-shell particles. Moreover, the characterization of the alloying is delicate, particularly for the smallest sizes. Bimetallic clusters often exhibit enhanced catalytic reaction rates and selectivity compared to the separate components. $^{4,5}$ For example, the turnover rate per surface Pd atom for the reaction between dihydrogen and dioxygen to form water was greater by a factor of 50 for the reaction over a supported AuPd catalyst than for Pd catalyst. ${ }^{4}$

Radiation-induced reduction of metal ions in solution has been demonstrated to be a powerful method to synthesize bimetallic clusters. ${ }^{2,6-8}$ However, by $\gamma$-radiolysis, a few systems as in chemical reduction were shown to yield intimately alloyed clusters. Indeed, an efficient competition is often occurring between the radiolytic reduction process of both types of ions and the electron-transfer reaction from the less noble metal atoms to the other metal ions. ${ }^{8-10}$ Then, this preferential reduction of the more noble metal first results in a segregation between the metals and eventually in a core-shell structure of the cluster with the more noble metal in the core. A sudden and complete reduction of both types of metal ions by a train of irradiation pulses prevents this kind of redox process through electron transfer. It was shown that in the same mixed ion system the metal clusters obtained change with increasing dose rate from a bilayered core/shell structure to an alloyed structure or bimetallic solid solution. ${ }^{10}$

In the literature, the combination of palladium with silver or gold are couples much studied. Bimetallic silver-palladium clusters have been prepared by various methods., ${ }^{71-13}$ The morphologies of gold/palladium mixed particles have been studied since the early 1970 s. ${ }^{14}$ When prepared by mixing the vapor phases, the two metals are miscible at any ratio as it can

* Author to whom correspondence should be addressed.

$\dagger$ IREM-Institut Lavoisier. be seen in their phase diagram. ${ }^{15}$ A gold-palladium mixed phase has been also condensed from the vapor into various solvents by chemical liquid deposition. ${ }^{16}$ The particle size was found to be solvent-dependent and lies between 2.5 and $3.8 \mathrm{~nm}$. In contrast, reported studies on reduction of salts in mixed solution lead systematically to core-shell particles. For example, $\mathrm{Au}($ core $) / \mathrm{Pd}($ shell) clusters were synthesized by reduction of the mixed ion aqueous ${ }^{17}$ or alcoholic solutions. ${ }^{18}$ Gold/palladium bimetallic particles having a palladium-rich shell were synthesized by Liu et al. ${ }^{19}$ Two-step alcoholic reduction gives "clusterin-cluster" structured products of the mixture of monometallic particles. ${ }^{20}$ The formation of core-thin-shell structures has been reported for large polymer-protected colloids ${ }^{18,19}$ and highly dispersed core/shell $\mathrm{Au} / \mathrm{Pd}$ clusters. ${ }^{21}$ Schmid et al. ${ }^{22}$ have demonstrated the controlled synthesis of core/shell $\mathrm{Au} / \mathrm{Pd}$ colloidal particles which are efficient catalysts for coupling and cyclization of acetylene, even at room temperature. Lee et al. ${ }^{23}$ synthesized a $\mathrm{Pd}-\mathrm{Au} / \mathrm{SiO}_{2}$ catalyst that contains bimetallic clusters consisting of Au-rich core decorated by $\mathrm{Pd}$ when the ionic precursors were reduced at $300{ }^{\circ} \mathrm{C}$ under $\mathrm{H}_{2}$. In contrast, the $\mathrm{Pd} / \mathrm{Au}$ catalyst that was reduced at $350{ }^{\circ} \mathrm{C}$ contained $\mathrm{Pd}-$ $\mathrm{Au}$ alloyed clusters. ${ }^{24}$

Photoreduction was also used for the preparation of mixed $\mathrm{Au} / \mathrm{Pd}$ core-shell particles. ${ }^{25}$ Sonochemical preparation of $\mathrm{Au}_{\text {core }} / \mathrm{Pd}_{\text {shell }}$ particles was reported recently. ${ }^{26,27}$ Transient monovalent palladium ions and palladium atoms are oxidized by gold ions by inter-metal electron transfer under sonication, so inhibiting the alloying. ${ }^{27}$ The same core-shell structure was also found by $\gamma$-irradiation of a mixed solution of gold(III) and palladium(II) ions. $^{27}$

As a matter of fact, it seems that alloyed clusters could be synthesized radiolytically from mixed solutions at high dose rate, when the ion reduction is sudden and faster than a possible inter-metal electron transfer. ${ }^{10}$ Therefore the aim of this work is to use pulse electron beams to irradiate gold-palladium ion mixed solutions and to get alloyed $\mathrm{Au}-\mathrm{Pd}$ clusters which were never obtained previously in solution. As the structure characterization of alloyed compared to core-shell nanoparticles is made difficult by the small size of these objects, we used for 
that purpose different complementary techniques, namely UVvis spectroscopy, XPS, and EDAX at increasing dose, that is at various stages of the cluster growth.

\section{Experimental Section}

The chemicals used are pure grade reagents. The metal salts are $\mathrm{KAuCl}_{4}$ (Degussa) and $\mathrm{PdCl}_{2}$ (CLAL). Poly(acrylic acid) (PA, MW 2000) (Aldrich) and poly(vinyl alcohol) (PVA, MW $86000,98 \%$ hydrolyzed, Aldrich) have been used as surfactants. The reduction is achieved in aqueous solution with added 2-propanol (Prolabo) to scavenge $\mathrm{OH}^{*}$ and $\mathrm{H}^{*}$ radicals and to produce secondary $\left(\mathrm{CH}_{3}\right)_{2} \mathrm{C} \cdot \mathrm{OH}$ radicals with strong reducing properties. Solutions were thoroughly deaerated by flushing with $\mathrm{N}_{2}$ gas. The $\gamma$-irradiations were carried out using a $7000 \mathrm{Ci}$ ${ }^{60} \mathrm{Co} \gamma$-source with a maximum dose rate of $6 \mathrm{kGy} \mathrm{h}^{-1}$. The irradiations at high dose rate were performed with a $20 \mathrm{~kW}-$ $10 \mathrm{MeV}$ electron accelerator (IONISOS-CARIC Society) delivering trains of $14 \mathrm{~ms}(10-350 \mathrm{~Hz})$ pulses through a scanning beam $\left(1-10 \mathrm{~Hz}\right.$ ) of mean dose rate $2.2 \mathrm{kGy} \mathrm{s}^{-1}$ (or $7.9 \mathrm{MGy}$ $\left.\mathrm{h}^{-1}\right)$.

UV-vis observations were performed with a Varian DMS100S spectrophotometer. TEM observations were performed with a JEPL 100CXII transmission electron microscope at an accelerating voltage of $100 \mathrm{kV}$, equipped with an Oxford Instruments energy dispersive spectrometer AN 10000 for X-ray analysis (EDAX). The sample drops were deposited and dried on carboncoated copper grids in the $\mathrm{N}_{2}$ atmosphere of a glovebox.

The XPS analysis has been performed on copper grids used for the TEM experiments. Each grid has been mounted on the sample holder with a carbon adhesive tape. The XPS analyzer was a ESCALAB 220i-XL. Either a nonmonochromatic or a monochromatic X-ray $\mathrm{Al} \mathrm{K} \alpha$ source is used for excitation. The photoelectrons are detected perpendicularly to the grid. A constant analyzer energy mode was used with pass energy of $20 \mathrm{eV}$. Note that the XPS analysis gives global information on all the particles of the sample, whereas EDAX is restricted to a few particles only.

\section{Results and Discussion}

The primary effects of the interaction of high-energy radiation such as particle beams and X-ray or $\gamma$ photons with a solution of metal ions are the excitation and the ionization of the solvent. For example, in aqueous solution:

$$
\begin{aligned}
& \mathrm{H}_{2} \mathrm{O} \stackrel{\gamma \text {, acc. } \mathrm{e}^{-}}{\longrightarrow} \mathrm{H}_{2} \mathrm{O}^{*}, \mathrm{H}_{2} \mathrm{O}^{+}, \mathrm{e}^{-} \rightarrow \\
& \mathrm{e}^{-}{ }_{\text {aq }}, \mathrm{H}_{3} \mathrm{O}^{+}, \mathrm{H}^{\cdot}, \mathrm{OH}^{\cdot}, \mathrm{H}_{2}, \mathrm{H}_{2} \mathrm{O}_{2}
\end{aligned}
$$

Solvated electrons $\left(\mathrm{e}^{-}\right.$aq $)$and $\mathrm{H}^{\cdot}$ radicals are strong reducing agents which can reduce metal ions to lower valencies and finally to metal atoms. Addition of radical scavengers such a secondary alcohol avoids reverse oxidation reactions by $\mathrm{OH}^{\cdot}$ radicals. Isopropyl alcohol yields by reaction with $\mathrm{OH}^{*}$ and $\mathrm{H}^{-}$ radicals a secondary reducing radical $\left(\mathrm{CH}_{3}\right)_{2} \mathrm{C} \cdot \mathrm{OH}$ :

$$
\left(\mathrm{CH}_{3}\right)_{2} \mathrm{CHOH}+\mathrm{OH}^{\cdot}\left(\mathrm{H}^{\cdot}\right) \rightarrow\left(\mathrm{CH}_{3}\right)_{2} \mathrm{C}^{\cdot} \mathrm{OH}+\mathrm{H}_{2} \mathrm{O}\left(\mathrm{H}_{2}\right)
$$

Metal ions $\left(\mathrm{M}^{+}\right)$can be reduced by solvated electrons or alcohol radicals:

$$
\begin{gathered}
\mathrm{e}_{\text {aq }}^{-}+\mathrm{M}^{+} \rightarrow \mathrm{M}^{0} \\
\left(\mathrm{CH}_{3}\right)_{2} \mathrm{C} \cdot \mathrm{OH}+\mathrm{M}^{+} \rightarrow\left(\mathrm{CH}_{3}\right)_{2} \mathrm{CO}+\mathrm{M}^{0}+\mathrm{H}^{+}
\end{gathered}
$$

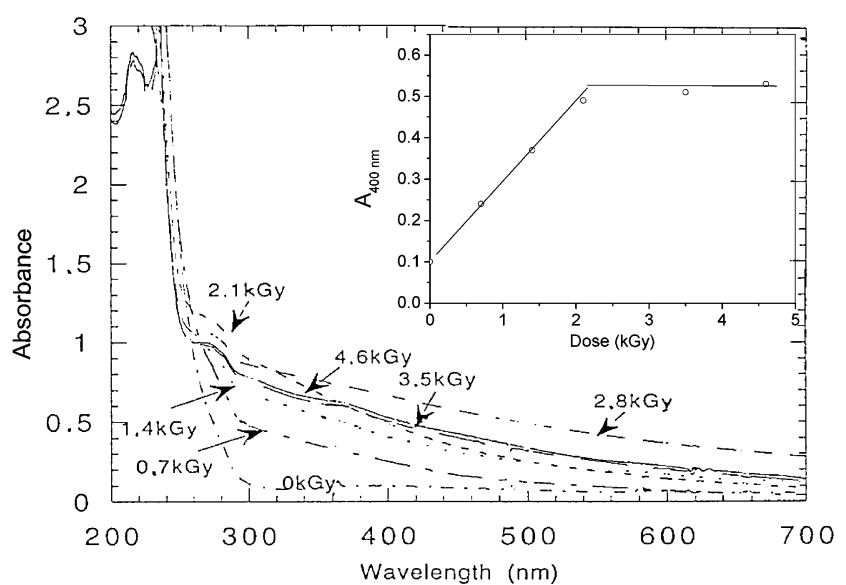

Figure 1. Evolution with increasing dose of the absorption spectra of a solution of $\mathrm{PdCl}_{2}$ irradiated at a $\gamma$-dose rate of $6 \mathrm{kGy} \mathrm{h}^{-1}$. $\left[\mathrm{Pd}^{\mathrm{II}}\right]=$ $10^{-3} \mathrm{~mol} \mathrm{~L}^{-1}$, [PA] $=10^{-1} \mathrm{~mol} \mathrm{~L}^{-1}$, [2-propanol] $=0.2 \mathrm{~mol} \mathrm{~L}^{-1}$. Optical path $=0.2 \mathrm{~cm}$. Inset: optical density at $400 \mathrm{~nm}$ as a function of irradiation dose.

Low Dose Rate Irradiations. The surface plasmon spectra of pure gold or palladium clusters are known to exhibit distinct resonance wavelengths. Gold clusters absorb in the visible with a maximum at around $510-520 \mathrm{~nm}$. The maximum of the UV plasmon band of palladium clusters has been calculated ranging around $205-220 \mathrm{~nm},{ }^{12}$ from the bulk dielectric data. ${ }^{28}$

For making possible the comparison with the mixed solutions, monometallic solutions of $\mathrm{Pd}^{\mathrm{II}}$ or $\mathrm{Au}^{\mathrm{III}}$ were first irradiated ${ }^{7,8,29}$ under the same conditions.

Figure 1 shows the evolution with increasing $\gamma$-dose of the optical absorption spectrum of a monometallic solution of palladium chloride $\left(10^{-3} \mathrm{~mol} \mathrm{~L}^{-1} \mathrm{Pd}^{\mathrm{II}}\right)$ in the presence of PA $\left(0.1 \mathrm{~mol} \mathrm{~L}^{-1}\right)$ and 2-propanol $\left(0.2 \mathrm{~mol} \mathrm{~L}^{-1}\right)$. The absorption spectrum keeps the same shape and the intensity increases in the whole wavelength domain up to a dose of $3.5 \mathrm{kGy}$. For example, at $500 \mathrm{~nm}$, the absorbance increases with the dose first linearly then reaches a plateau corresponding to complete reduction. From the value of $A_{400 \mathrm{~nm}}\left(\mathrm{Pd}_{n}\right)$ at the plateau, the molar extinction coefficient per atom is $\epsilon\left(\mathrm{Pd}_{n}\right)_{400}=2600 \mathrm{~L}$ $\mathrm{mol}^{-1} \mathrm{~cm}^{-1}$. The reduction yield $\mathrm{G}\left(\mathrm{Pd}_{n}\right)$ is deduced from the slope of the initial linear increase of $A_{400 \mathrm{~nm}}\left(\mathrm{Pd}_{n}\right)$ with the dose and is found to be equal to 3 atoms or 6 equivalents $/ 100 \mathrm{eV}(6$ $\left.\times 10^{-7} \mathrm{~mol} \mathrm{~J}^{-1}\right)$. This yield corresponds to the scavenging of $\mathrm{e}^{-}$aq and $\left(\mathrm{CH}_{3}\right)_{2} \mathrm{C} \cdot \mathrm{OH}$ radicals according to the reduction reactions (eqs 3,4$)$ :

$$
\begin{gathered}
\mathrm{Pd}^{\mathrm{II}}+\mathrm{e}_{\text {aq }}^{-} \rightarrow \mathrm{Pd}^{\mathrm{I}} \\
\mathrm{Pd}^{\mathrm{II}}+\left(\mathrm{CH}_{3}\right)_{2} \mathrm{C}^{\cdot} \mathrm{OH} \rightarrow \mathrm{Pd}^{\mathrm{I}}+\left(\mathrm{CH}_{3}\right)_{2} \mathrm{CO}+\mathrm{H}^{+} \\
2 \mathrm{Pd}^{\mathrm{I}} \rightarrow \mathrm{Pd}^{0}+\mathrm{Pd}^{\mathrm{II}}
\end{gathered}
$$

Charged dimers such as $\mathrm{Pd}_{2}{ }^{+}$or $\mathrm{Pd}_{2}{ }^{2+}$ which are formed by association of atoms with ions are also progressively reduced. Coalescence of these oligomers leads to the stable clusters $\operatorname{Pd}_{n}$.

The TEM micrograph of the palladium clusters is shown in Figure 2a. The distribution is homogeneous in size and the mean diameter is $2 \mathrm{~nm}$.

The spectral evolution of $\mathrm{Au}^{\mathrm{III}}$ solutions $\left(10^{-3} \mathrm{~mol} \mathrm{~L}^{-1}\right.$ $\left.\mathrm{KAuCl}_{4}\right)$ in the presence of PVA $\left(0.1 \mathrm{~mol} \mathrm{~L}^{-1}\right)$ with increasing dose was already reported in detail. ${ }^{29} \mathrm{We}$ repeated the experiments in the presence of the same polymer as for $\mathrm{Pd}^{\mathrm{II}}$, that is PA (Figure 3, inset). The extinction coefficient at $520 \mathrm{~nm}$ is $\epsilon\left(\mathrm{Au}_{n}\right)_{520}=2800 \mathrm{~L} \mathrm{~mol}^{-1} \mathrm{~cm}^{-1}$. The dose required for the total 
Dose Rate Effect on $\mathrm{Au}-\mathrm{Pd}$ Cluster Structure
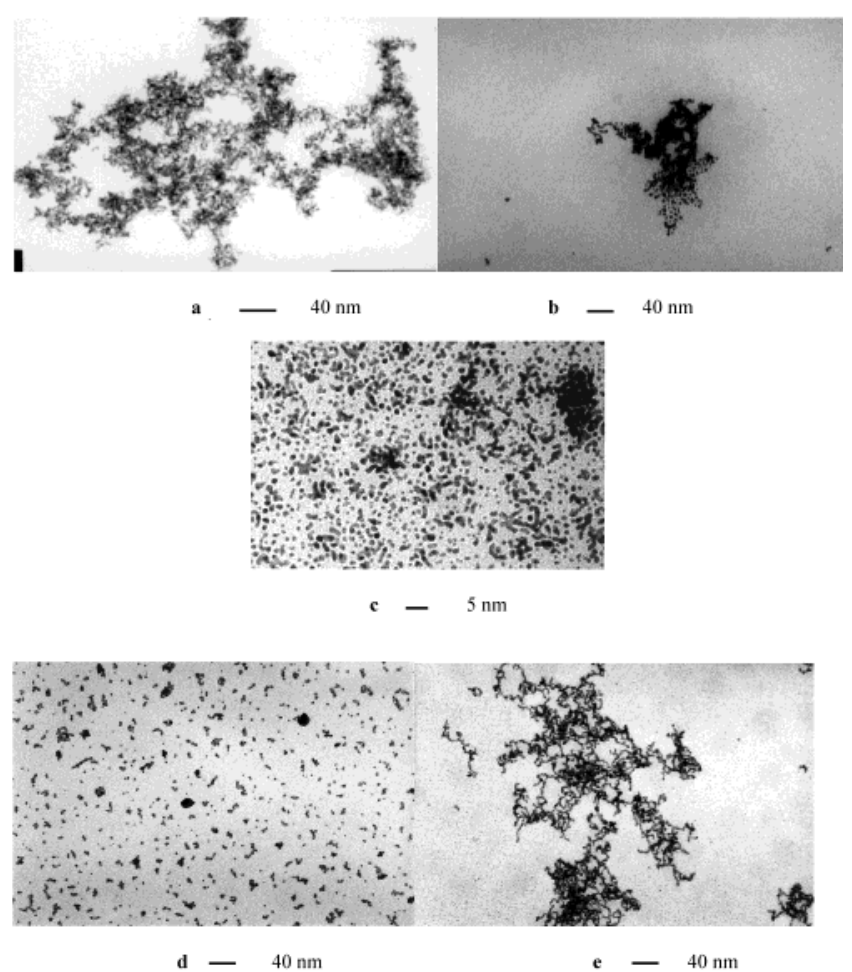

Figure 2. Micrographs of (a) palladium clusters stabilized by PA. [Pd $\left.{ }^{\mathrm{II}}\right]$ $=10^{-3} \mathrm{~mol} \mathrm{~L}^{-1},[\mathrm{PA}]=10^{-1} \mathrm{~mol} \mathrm{~L}^{-1}$, [2-propanol] $=0.2 \mathrm{~mol} \mathrm{~L}^{-1}$, $\gamma$-dose $=3.5 \mathrm{kGy}$; (b) palladium - gold clusters stabilized by PA. [ $\left.\mathrm{Pd}^{\mathrm{II}}\right]$ $=\left[\mathrm{Au}^{\mathrm{III}}\right]=10^{-3} \mathrm{~mol} \mathrm{~L}^{-1},[\mathrm{PA}]=10^{-1} \mathrm{~mol} \mathrm{~L}^{-1},[2$-propanol $]=0.2$ mol L ${ }^{-1}$, dose $=8.5 \mathrm{kGy}$; (c) palladium - gold clusters stabilized by PA and synthesized by electron beam (dose rate $\left.2.2 \mathrm{kGy} \mathrm{s}^{-1}\right),\left[\mathrm{Pd}^{\mathrm{II}}\right]=$ $\left[\mathrm{Au}^{\mathrm{III}}\right]=10^{-3} \mathrm{~mol} \mathrm{~L}^{-1},[\mathrm{PA}]=10^{-1} \mathrm{~mol} \mathrm{~L}^{-1}$, dose $=8.5 \mathrm{kGy} ;(\mathrm{d})$ palladium-gold clusters synthesized by electron beam (dose rate 2.2 $\left.\mathrm{kGy} \mathrm{s}^{-1}\right),[2$-propanol $]=0.2 \mathrm{~mol} \mathrm{~L}^{-1},\left[\mathrm{Pd}^{\mathrm{II}}\right]=\left[\mathrm{Au}^{\mathrm{III}}\right]=5 \times 10^{-4}$ mol L ${ }^{-1}$, dose $=5 \mathrm{kGy}$; (e) palladium - gold clusters synthesized by electron beam, $[2$-propanol $]=0.2 \mathrm{~mol} \mathrm{~L}^{-1},\left[\mathrm{Pd}^{\mathrm{II}}\right]=\left[\mathrm{Au}^{\mathrm{II}}\right]=2.5 \times$ $10^{-3} \mathrm{~mol} \mathrm{~L}^{-1}$, dose $=25 \mathrm{kGy}$. reduction is $5.3 \mathrm{kGy}$. The reduction yield for $\mathrm{Au}^{\mathrm{III}}$ to $\mathrm{Au}^{0}$ was found to be also 6 equivalents $/ 100 \mathrm{eV}\left(6 \times 10^{-7} \mathrm{~mol} \mathrm{~J}^{-1}\right)$. According to the previous study: ${ }^{29}$

$$
\begin{gathered}
\mathrm{Au}^{\mathrm{III}}+\mathrm{e}^{-}{ }_{\mathrm{aq}} \rightarrow \mathrm{Au}^{\mathrm{II}} \\
\mathrm{Au}^{\mathrm{III}}+\left(\mathrm{CH}_{3}\right)_{2} \mathrm{C} \cdot \mathrm{OH} \rightarrow \mathrm{Au}^{\mathrm{II}}+\left(\mathrm{CH}_{3}\right)_{2} \mathrm{CO}+\mathrm{H}^{+} \\
2 \mathrm{Au}^{\mathrm{II}} \rightarrow \mathrm{Au}^{\mathrm{I}}+\mathrm{Au}^{\mathrm{III}} \\
\mathrm{Au}^{\mathrm{I}}+\mathrm{e}^{-}{ }_{\mathrm{aq}} \rightarrow \mathrm{Au}^{0} \\
\mathrm{Au}^{\mathrm{I}}+\left(\mathrm{CH}_{3}\right)_{2} \mathrm{C} \cdot \mathrm{OH} \rightarrow \mathrm{Au}^{0}+\left(\mathrm{CH}_{3}\right)_{2} \mathrm{CO}+\mathrm{H}^{+} \\
\mathrm{Au}^{\mathrm{I}}+\mathrm{Au}^{0} \rightarrow \mathrm{Au}_{2}^{+}
\end{gathered}
$$

Progressive reduction of $\mathrm{Au}_{2}{ }^{+}$and coalescence of oligomers lead to $\mathrm{Au}_{n}$. The mean size of $\gamma$-synthesized gold particles measured by TEM is around 3-4 $\mathrm{nm}$.

The evolution at increasing dose of the optical spectra of an equimolar mixed solution of $\mathrm{KAuCl}_{4}$ and $\mathrm{PdCl}_{2}\left(10^{-3}\right.$ mol L ${ }^{-1}$ $\mathrm{Au}^{\mathrm{III}} / 10^{-3} \mathrm{~mol} \mathrm{~L}^{-1} \mathrm{Pd}^{\mathrm{II}}$ ) irradiated by $\gamma$-rays in the presence of PA up to total ion reduction is presented in Figure 3. Up to a dose of $3.5 \mathrm{kGy}$, the optical spectrum is first identical to the surface plasmon spectrum of pure gold clusters with the specific maximum at $520 \mathrm{~nm}$. At that dose, about $70 \%$ of gold ions are reduced. Then, the intensity continues to increase but the typical

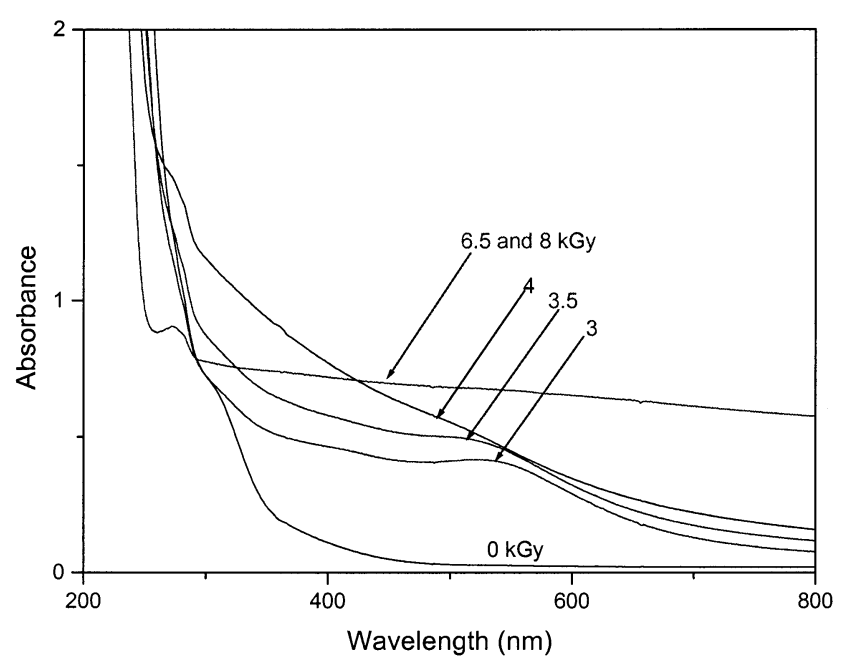

Figure 3. Evolution with increasing dose of the absorption spectra of a mixed $\mathrm{Au}^{\mathrm{III}} / \mathrm{Pd}^{\mathrm{II}}(50 / 50)$ solution of total metal concentration $2 \times$ $10^{-3} \mathrm{~mol} \mathrm{~L}^{-1}$ irradiated at a dose rate $6 \mathrm{kGy} \mathrm{h}^{-1}\left[\mathrm{Pd}^{\mathrm{II}}\right]=\left[\mathrm{Au}^{\mathrm{III}}\right]=$ $10^{-3} \mathrm{~mol} \mathrm{~L}^{-1},[\mathrm{PA}]=10^{-1} \mathrm{~mol} \mathrm{~L}^{-1}$, [2-propanol $]=0.2 \mathrm{~mol} \mathrm{~L}^{-1}$, optical path $=0.2 \mathrm{~cm}$.

absorption maximum at $520 \mathrm{~nm}$ disappears progressively and the final spectrum is close to the surface plasmon spectrum of pure palladium clusters. The spectral evolution indicates indeed that the cluster composition changes when the dose increases from almost pure gold clusters $(0-3.5 \mathrm{kGy})$ to clusters coated with an increasing surface layer rich in palladium. The micrograph presented in Figure $2 \mathrm{~b}$ indicates that the particles obtained by irradiation of mixed $\mathrm{KAuCl}_{4}$ and $\mathrm{PdCl}_{2}$ solutions at low dose rate are isolated one from each other and that their size is 3-4 $\mathrm{nm}$.

In all cases, Pd and Au XPS spectra are detected. However, we essentially used the $\mathrm{Au}_{4 \mathrm{f}}$ and $\mathrm{Pd}_{3 \mathrm{~d}}$ signals as they are shown in Figures 4A and 4B, respectively. The peak positions are close to the ones reported in the literature. In the $\mathrm{Pd}_{3 \mathrm{~d}}$ region a peak overlap occurs between the $\mathrm{Pd}_{3 \mathrm{~d} 5 / 2}$ and the $\mathrm{Au}_{4 \mathrm{~d} 5 / 2}$ core levels. So, to establish the experimental elemental concentration ratios between $\mathrm{Pd}$ and $\mathrm{Au}$ atoms, we used the $\mathrm{Pd}_{3 \mathrm{~d} 3 / 2}$ and the $\mathrm{Au}_{4 \mathrm{f}} 3 / 2$ or $5 / 2$ peak areas, corrected by their VG $220 \mathrm{i}$ specific sensitivity factors.

When the estimated cluster diameter is lower than $3 \mathrm{~nm}$, the XPS ratio corresponds to an analysis of the total depth of the particle and is very close to the global composition ratio expected from that of ionic precursors. For these reasons, in these cases, the segregation effects between the core and the outer parts of the clusters are not directly detected, but only suggested by slight variations of the Pd/Au ratio. For the AuPd$1,-2$, and -3 samples (Table 1 ), the particles have indeed a size of $2-3 \mathrm{~nm}$ and the ratios of $\mathrm{Pd} / \mathrm{Au}$ obtained by XPS are close to the overall chemical composition of the clusters.

To discriminate between the shell and the core by XPS analysis, we therefore synthesized larger clusters from solutions containing lower polymer concentration (samples AuPd-3 and -4) and even without polymer (samples AuPd-5). Sizes of 3 to $>10 \mathrm{~nm}$ were found. Indeed in these cases, the XPS method allows us to analyze essentially the upper shell of the cluster. An external enrichment of Pd can be detected according to the increase of the $\mathrm{Pd} / \mathrm{Au}$ ratio with dose found by spectrophotometry, indicating a Pd enrichment in the cluster outer shell. In agreement with this enrichment, $\mathrm{Pd}-\mathrm{O}$ chemical bonds can be detected according to the presence of a $3 \mathrm{eV}$ shifted contribution for the $\mathrm{Pd}_{3 \mathrm{~d}}$ peaks as shown in Figure 4B (b) (AuPd-2). Similar comments can be done for the AuPd-5 sample. In that case, the 
TABLE 1. XPS and TEM Characterization of Bimetallic Au/Pd Clusters Prepared by $\gamma$-Irradiation at Various Dose, Ion, and Polymer Concentration

\begin{tabular}{|c|c|c|c|c|c|c|c|}
\hline sample $^{a}$ & $\begin{array}{l}\text { dose } \\
(\mathrm{kGy})\end{array}$ & $\begin{array}{l}\text { total }[\mathrm{M}] \\
(\mathrm{M})\end{array}$ & $\begin{array}{c}{[\mathrm{PA}]} \\
(\mathrm{M})\end{array}$ & $\begin{array}{c}\mathrm{Pd} / \mathrm{Au} \\
\text { precursor ratio }\end{array}$ & $\begin{array}{c}\text { cluster size } \\
\text { by TEM }(\mathrm{nm})\end{array}$ & $\begin{array}{c}\text { XPS } \\
\text { composition } \mathrm{Pd} / \mathrm{Au}\end{array}$ & structure \\
\hline AuPd-1 & 5 & $10^{-3}$ & $10^{-1}$ & $50 / 50$ & $2-3$ & $51 / 49$ & \\
\hline AuPd-2 & 5 & $10^{-3}$ & $10^{-1}$ & $25 / 75$ & $2-3$ & $29 / 71$ & \\
\hline AuPd-3 & 10 & $2 \times 10^{-3}$ & $10^{-2}$ & $50 / 50$ & 3 & $49.4 / 50.6$ & \\
\hline AuPd-4 & 10 & $2 \times 10^{-3}$ & $2 \times 10^{-3}$ & $50 / 50$ & 5 & $65 / 35$ & outer shell: $\mathrm{Pd}$ \\
\hline AuPd-5 & 10 & $2 \times 10^{-3}$ & 0 & $50 / 50$ & $>10$ & $89 / 11$ & outer shell: Pd \\
\hline
\end{tabular}

${ }^{a}$ All samples contain in addition 2-propanol at $0.2 \mathrm{M}$.
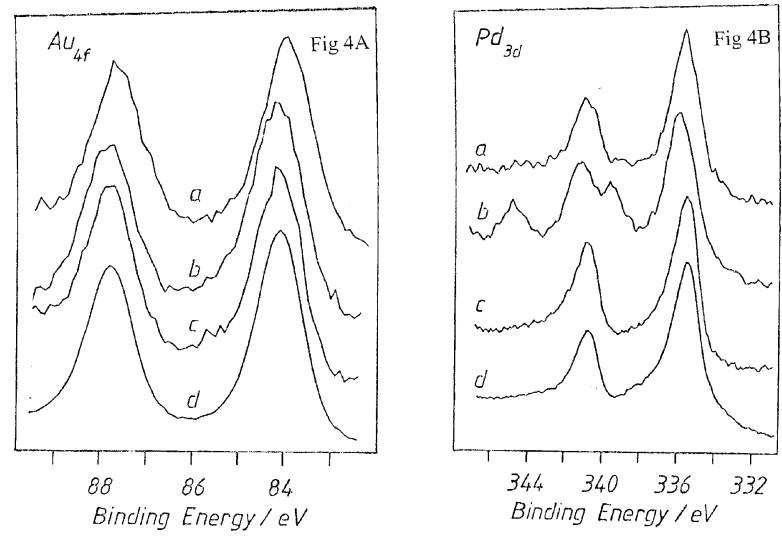

Figure 4. XPS core level spectra of $\mathrm{Au}_{4 \mathrm{f}}(\mathrm{A})$ and $\mathrm{Pd}_{3 \mathrm{~d}}(\mathrm{~B})$ for several Au/Pd samples. (a) AuPd-1; (b) AuPd-2; (c) AuPd-6; (d) AuPd-7 (see Tables 1 and 2).
Pd enrichment of the upper shell of the cluster is clearly established as a result of the larger size of the cluster sample.

Therefore, we conclude that at low dose rate, when Pd and $\mathrm{Au}$ ions are slowly reduced (reactions 5-13), in addition a concomitant electron transfer from $\mathrm{Pd}^{\mathrm{I}}$ or/and $\mathrm{Pd}^{0}$ to gold ions $\mathrm{Au}^{\mathrm{III}}$ and $\mathrm{Au}^{\mathrm{I}}$ which are predominantly present favors systematically the reduction of gold first:

$$
\begin{gathered}
\mathrm{Pd}^{\mathrm{I}}+\mathrm{Au}^{\mathrm{III}} \rightarrow \mathrm{Pd}^{\mathrm{II}}+\mathrm{Au}^{\mathrm{II}} \\
\mathrm{Pd}^{\mathrm{I}}+\mathrm{Au}^{\mathrm{I}} \rightarrow \mathrm{Pd}^{\mathrm{II}}+\mathrm{Au}^{0} \\
\mathrm{Pd}^{0}+\mathrm{Au}^{\mathrm{III}} \rightarrow \mathrm{Pd}^{\mathrm{I}}+\mathrm{Au}^{\mathrm{II}} \\
\mathrm{Pd}^{0}+\mathrm{Au}^{\mathrm{I}} \rightarrow \mathrm{Pd}^{\mathrm{I}}+\mathrm{Au}^{0}
\end{gathered}
$$

In the meantime, gold atoms coalesce and gold clusters grow. When gold ions are almost totally reduced, Pd ions adsorb on the gold cluster surface where they are further reduced by radiolytic species, producing $\mathrm{Au}_{\text {core }} / \mathrm{Pd}_{\text {shell }}$ clusters:

$$
\begin{gathered}
\mathrm{Au}_{n}+m \mathrm{Pd}^{\mathrm{II}} \rightarrow \mathrm{Au}_{n} \mathrm{Pd}_{m}{ }^{2 m+} \\
\mathrm{Au}_{n} \mathrm{Pd}_{\mathrm{m}}{ }^{2 m+}+\mathrm{e}^{-} \text {aq } \text { or }\left(\mathrm{CH}_{3}\right)_{2} \mathrm{C} \cdot \mathrm{OH} \rightarrow \mathrm{Au}_{n} \mathrm{Pd}_{m}
\end{gathered}
$$

High Dose Rate Irradiation (electron pulse train). The evolution at increasing dose of the optical absorption spectrum of an equimolar mixed $\mathrm{Au}^{\mathrm{III}} / \mathrm{Pd}^{\mathrm{II}}$ solution $\left(\left(10^{-3} \mathrm{~mol} \mathrm{~L}^{-1} \mathrm{Au}^{\mathrm{III}}\right) /\right.$ $\left.\left(10^{-3} \mathrm{~mol} \mathrm{~L}^{-1} \mathrm{Pd}^{\mathrm{II}}\right)\right)$ irradiated by an electron beam at a much higher dose rate $\left(2.2 \mathrm{kGy} \mathrm{s}^{-1}\right)$ than with the $\gamma$-source is presented in Figure 5. When mixed solutions of $\mathrm{KAuCl}_{4}$ and $\mathrm{PdCl}_{2}$ are irradiated in the presence of PA or PVA at high dose rate, the band intensity progressively increases with the dose in a similar way at any wavelength up to complete reduction, except in the UV where the ionic precursors or the polymer absorb (Figure 3). Particularly at low doses, a maximum is

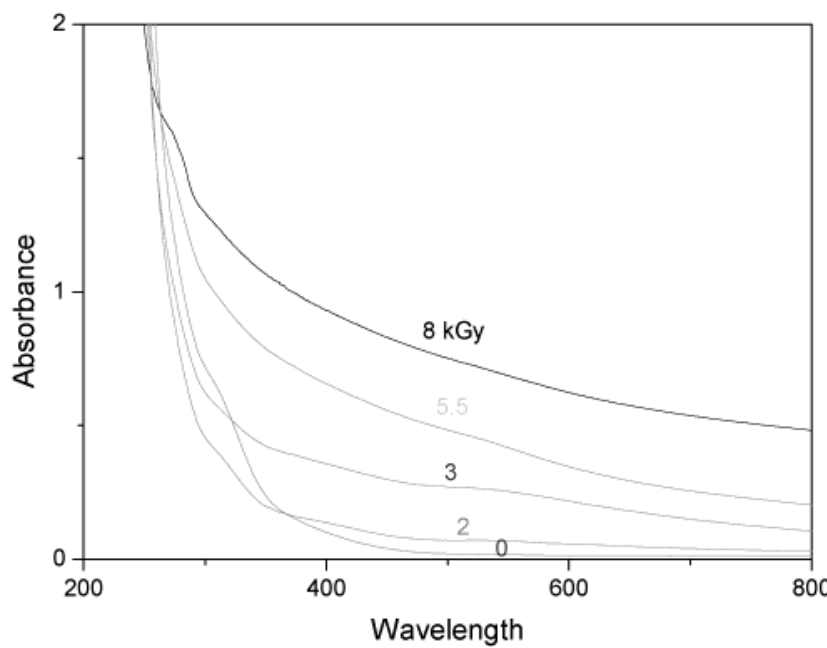

Figure 5. Evolution with increasing dose of the absorption spectra of a mixed $\mathrm{Au}^{\mathrm{III}} / \mathrm{Pd}^{\mathrm{II}}(50 / 50)$ solution of total metal concentration $2 \times$ $10^{-3} \mathrm{~mol} \mathrm{~L}^{-1}$ irradiated by electron beam at a dose rate $2.2 \mathrm{kGy} \mathrm{s}^{-1}$ $\left[\mathrm{Pd}^{\mathrm{II}}\right]=\left[\mathrm{Au}^{\mathrm{III}}\right]=10^{-3} \mathrm{~mol} \mathrm{~L}^{-1},[\mathrm{PA}]=2 \times 10^{-1} \mathrm{~mol} \mathrm{~L}^{-1}$, [2-propanol $]$ $=0.2 \mathrm{~mol} \mathrm{~L}^{-1}$, Optical path $=0.2 \mathrm{~cm}$.

observed at $315 \mathrm{~nm}$ associated with $\mathrm{Au}^{\mathrm{III}} \mathrm{Cl}_{4}{ }^{-}$until $6 \mathrm{kGy}$. No maximum is detected around $520 \mathrm{~nm}$ even at the lower doses, in contrast with $\gamma$-irradiation experiments (Figure 3). This spectral evolution strongly supports that gold is not preferentially formed at low dose and that, indeed, palladium and gold ions are reduced simultaneously from the beginning of irradiation and that both metals are alloyed in the same cluster at any dose.

The UV-vis spectra of $\mathrm{Au}_{x} / \mathrm{Pd}_{1-x}$ clusters formed in solutions with different $\mathrm{Au}{ }^{\mathrm{III}} / \mathrm{Pd}^{\mathrm{II}}$ compositions were studied similarly at different doses up to complete reduction. The UV-vis spectra of $\mathrm{Au} / \mathrm{Pd}$ clusters obtained with variable $x$ precursor ratio $\mathrm{Au}^{\mathrm{III}}{ }_{x} /$ $\mathrm{Pd}^{\mathrm{II}}{ }_{1-x}(x=1$ to 0.25$)$ at total reduction is presented in Figure 6. At a given ratio, and a variable dose, the spectra display the same shape. For high relative content of gold $\mathrm{x}=1$ to 0.9 , a maximum at $520 \mathrm{~nm}$ is observed at any dose (Figure 6).

Other samples have been prepared with lower values of the $\mathrm{Au}^{\mathrm{III}} / \mathrm{Pd}^{\mathrm{II}}{ }_{1-x}$ ratio, from $x=0.80$ to 0.25 . Again, the intensity of the absorption spectrum progressively increases with the dose in a similar way for all wavelengths (except in the absorption region of the ionic precursors). No maximum is obtained at 520 $\mathrm{nm}$, even at low doses.

The micrographs presented in Figure $2 \mathrm{c}$ indicate that the particles obtained by irradiation of mixed $\mathrm{KAuCl}_{4}$ and $\mathrm{PdSO}_{4}$ solutions at high dose rate are isolated one from each other and their size is $2-3 \mathrm{~nm}$, which is intermediate between that of pure gold clusters $(4 \mathrm{~nm})$ and of pure palladium clusters $(1-2$ $\mathrm{nm}$ ) obtained under the same conditions of concentration and dose. When compared to mixed particles obtained at low dose rate (Figure $2 b$ ), under identical conditions of concentration and dose, these clusters are also smaller.

Local X-ray analysis of the particles obtained at different doses of an equimolar $\mathrm{Au}^{\mathrm{III}}{ }_{x} / \mathrm{Pd}^{\mathrm{II}}{ }_{1-x}$ solution $(x=0.5)$ indicate, 
TABLE 2: XPS and TEM Characterization of Bimetallic Au/Pd Clusters Prepared by Irradiation at High Dose Rate (electron beam) at Various Dose and Polymer Concentration

\begin{tabular}{|c|c|c|c|c|c|c|c|}
\hline sample $^{a}$ & $\begin{array}{l}\text { dose } \\
(\mathrm{kGy})\end{array}$ & $\begin{array}{l}{[\mathrm{M}]} \\
(\mathrm{M})\end{array}$ & $\begin{array}{l}{[\mathrm{APA}]} \\
(\mathrm{M})\end{array}$ & $\begin{array}{c}\mathrm{Pd} / \mathrm{Au} \\
\text { precursor ratio }\end{array}$ & $\begin{array}{c}\text { cluster size } \\
\text { by TEM }(\mathrm{nm})\end{array}$ & $\begin{array}{c}\text { XPS } \\
\text { composition } \mathrm{Pd} / \mathrm{Au}\end{array}$ & structure \\
\hline AuPd-6 & 8 & $2 \times 10^{-3}$ & $2 \times 10^{-3}$ & $75 / 25$ & $2-3$ & $83 / 17$ & \\
\hline AuPd-7 & 8 & $2 \times 10^{-3}$ & $2 \times 10^{-3}$ & $50 / 50$ & $2-3$ & $44 / 56$ & \\
\hline AuPd-8 & $\begin{array}{l}5.5 \text { (partial } \\
\text { reduction) }\end{array}$ & $2 \times 10^{-3}$ & $10^{-1}$ & $50 / 50$ & $2-3$ & $40 / 60$ & $\mathrm{Au}-\mathrm{Pd}$ alloy \\
\hline
\end{tabular}

${ }^{a}$ All samples contain in addition 2-propanol at $0.2 \mathrm{M}$.

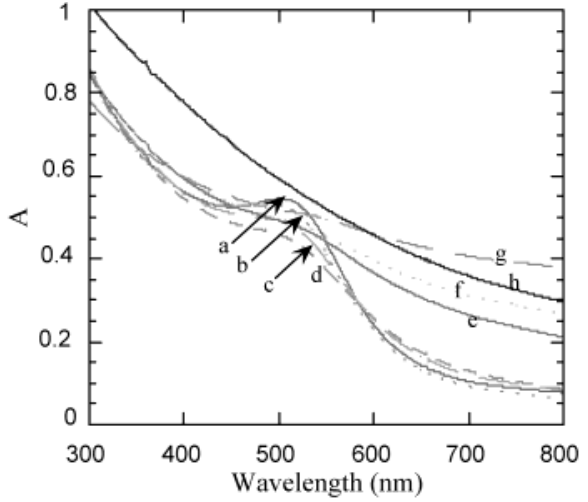

Figure 6. Absorption spectra of mixed $\mathrm{A} u_{\mathrm{x}} \mathrm{III} / \mathrm{Pd}_{1-x}$ II solutions of total metal concentration $2 \times 10^{-3} \mathrm{~mol} \mathrm{~L}^{-1}$ at various proportions $(x$ from 1 to 0 ) and irradiated at complete reduction by electron beam (dose rate $\left.2.2 \mathrm{kGy} \mathrm{s}^{-1}\right)$. [PA] $=2 \times 10^{-1} \mathrm{~mol} \mathrm{~L}^{-1},[2$-propanol $]=0.2 \mathrm{~mol}$ $\mathrm{L}^{-1}$, optical path $=0.2 \mathrm{~cm}$. (a) $x=1$; (b) $x=0.99$; (c) $x=0.95$; (d) $x=0.9$; (e) $x=0.88$; (f) $x=0.85$; (g) $x=0.8$; (h) $x=0$. even at low doses, an average composition of $50 \%$ of each of the elements $\mathrm{Au}$ and $\mathrm{Pd}$ (the composition of individual particles lies in the interval $35 / 65$ to $65 / 35$ for the $\mathrm{Au} / \mathrm{Pd}$ ratio). These results confirm that after high dose rate irradiation both types of metal atoms are intimately alloyed in the clusters. The electron scattering data corresponding to a dense cluster area present indeed the typical Debye-Sherrer patterns of solid solutions.

The EDAX results indicate that the average composition of clusters in $\mathrm{Au}$ and $\mathrm{Pd}$ does not change during the irradiation time and is close to that of the ionic precursors before irradiation.

To obtain larger particles, electron beam irradiation of metal ion solutions (total ion concentration of $5 \times 10^{-3} \mathrm{M}$ ) have been achieved without the presence of polymer (Table 2). Chloride ions adsorbed on the metal clusters are the only stabilizer against growth and flocculation. The drops were dried on grids immediately after the end of irradiation. In Figure $2 d$ is shown a micrograph of the particles obtained by irradiation of an equimolar solution $(x=0.5)$ of total concentration of metal salts of $5 \times 10^{-3} \mathrm{M}$ with a dose of $5 \mathrm{kGy}$. The particles are still individual and the mean diameter is $3 \mathrm{~nm}$. Figure $2 \mathrm{e}$ shows that the particles obtained by irradiation of a more concentrated ionic solution (total ion concentration of $5 \times 10^{-3} \mathrm{M}$ ) are still small $(3-4 \mathrm{~nm})$. In this case, the clusters are not isolated one from each other: when deposited on the carbon grids they are associated as necklaces with a fractal pattern. Local X-ray analysis of the particles obtained at 5 and $25 \mathrm{kGy}$ indicate for both samples an average composition of $50 \%$ of both metals. Other solutions with initial $\mathrm{Au}_{x}{ }^{\mathrm{III}} / \mathrm{Pd}_{1-x}{ }^{\mathrm{II}}$ ratios: $x=0.75$ and 0.25 at higher total metal concentration $\left(10^{-2} \mathrm{~mol} \mathrm{~L}^{-1}\right)$ were irradiated without polymer at high dose rate. Local X-ray analysis of the particles obtained at increasing dose indicate also for both samples an average composition close to that of the ionic precursors. Note that the same solutions irradiated with $\gamma$-rays lead to flocculation of the particles which deposit.

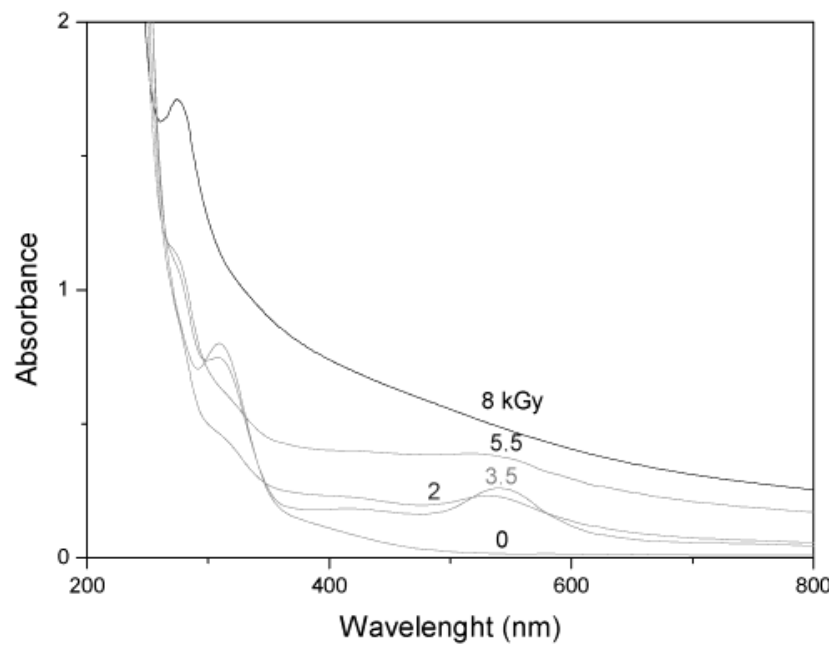

Figure 7. Evolution with dose of absorption spectra of mixed AuII/ $\mathrm{Pd}^{\mathrm{II}}$ solutions of total metal concentration $2 \times 10^{-3} \mathrm{~mol} \mathrm{~L}^{-1}$ with excess of chloride ions $\left(\mathrm{HCl}, \mathrm{pH}_{\text {final }}=2\right)$ irradiated by electron beam (dose rate $2.2 \mathrm{kGy} \mathrm{s}^{-1}$ ). [PA] $=2 \times 10^{-1} \mathrm{~mol} \mathrm{~L}^{-1}$, [2-propanol] $=0.2 \mathrm{~mol}$ $\mathrm{L}^{-1}$, optical path $=0.2 \mathrm{~cm}$.

Because the cluster size is small, the XPS results give the same information as EDX results, except that chemical bonds with oxygen are typical of the surface metal atoms. We observed that the composition values change from $83 / 17$ to $40 / 60$ and are close to the initial ratio of the metal precursors. As for samples AuPd-4 and -5 (Table 1), it seems that a very slight $\mathrm{Pd}$ enrichment in the cluster outer shell is observed in agreement with $\mathrm{Pd}-\mathrm{O}$ chemical bonds for the sample AuPd-6.

To get information by XPS on the structure of the particles despite their very small size under electron beam reduction, the analysis has been performed also on sample 8 (Table 2) which was obtained at partial reduction. The dose was chosen to be equal to $5 \mathrm{kGy}$, which is the dose required to reduce all gold ions in the case of a preferential reduction of gold as with $\gamma$-rays. In contrast, the XPS analysis of the particles obtained at this dose with electron beam reduction indicates that they contain gold and also palladium in a proportion close to the initial ion ratio. These results support $\mathrm{Au}-\mathrm{Pd}$ alloying in agreement with EDAX analysis and UV-vis spectra observations.

At high dose rate, the complete reduction of palladium and gold ions (reactions 5-13) and the coalescence of both types of atoms are fast enough to make negligible the electron transfer from Pd atoms to Au ions (reactions 14-17). Therefore Pd and $\mathrm{Au}$ atoms are included in the cluster with the same ratio as the ionic precursors from the early stage of the growth.

Effect of Chloride Concentration. Experiments at high dose rates have been done in the presence of a large excess of chloride ions obtained either by acidification of palladium solution with $\mathrm{HCl}$ or by addition of $\mathrm{NaCl}$ salts. It is known that by acidification with $\mathrm{HCl}$ or in excess of $\mathrm{Cl}^{-}$ions $\mathrm{PdCl}_{2}$ is converted into $\mathrm{PdCl}_{4}{ }^{2-}$ complexes. The spectral evolution of the mixed solution $\mathrm{Au}{ }^{\mathrm{III}} / \mathrm{Pd}^{\mathrm{II}}$ in excess of chloride ions is shown 
F J. Phys. Chem. B PAGE EST: 5.6

in Figure 7. Surprisingly, although the irradiation is achieved suddenly by electron pulse train, the optical absorption spectrum displays a maximum at $520 \mathrm{~nm}$ at low doses (up to a dose of $5.5 \mathrm{kGy}$ ), identical to that of pure gold clusters. At higher dose the maximum disappears and the shape of the spectrum is close to that of pure palladium. This clearly suggests that, even ions are quickly reduced into atoms at this dose rate, a preferential reduction of gold occurs first. Unlike in previous results, when excess $\mathrm{Cl}^{-}$are present, it seems that the electron transfer from $\mathrm{Pd}^{\mathrm{I}}$ or $\mathrm{Pd}^{0}$ chloro-complexes to gold ions is still efficient as in reactions $14-17$.

\section{Conclusion}

The use of radiation-induced synthesis allows us to control the reduction rate through the dose rate conditions. Despite the very small size of the clusters, their structure is determined from optical spectroscopy or XPS by studying the clusters at different absorbed doses, that is at different stages of the ion reduction and of the cluster growth. The metal clusters obtained from the same mixed system change from a bi-layered $\mathrm{Au}_{\text {core }} / \mathrm{Pd}_{\text {shell }}$ structure at low dose rate (and at high dose rate with excess of chloride ions) to an alloyed solid solution with the increase of the dose rate of a train of electron pulses. The extremely fast reduction achieved by electron pulses prevents the electron transfer from nascent palladium atoms to gold ions and thus any segregation. To our knowledge, it is the first time that AuPd alloyed clusters are obtained by ion reduction in solution at room temperature. This study also confirms that the clusters obtained at high dose rate are smaller and very homogeneous in size.

Acknowledgment. The authors are gratefully indebted to P. Beaunier, Groupement Régional de Mesures Physiques, Paris VI, for her contribution in characterization experiments through electron microscopy and diffraction or X-analysis.

\section{References and Notes}

(1) Sinfelt, J. H. Bimetallic Catalysts-Discoveries, Concepts, and Applications; Exxon Monograph, Wiley: New York, 1983.

(2) Belloni, J.; Mostafavi, M.; Remita, H.; Marignier, J. L.; Delcourt, M. O. New J. Chem. 1998, 22, 1239.
(3) Belloni, J. Mostafavi, M. In Radiation Chemistry: Present status and future trends; Jonah, C. D., Rao, M., Eds.; Elsevier: Amsterdam, 2001; p 411.

(5) Davis, R. J.; Boudart, M. In Catalytic Science and Technology; 394 Yoshida, S., Takezawa N., Ono, T., Eds.; Kodansha: Tokyo, 1991; Vol. 1, 395 p 129.

(6) Marignier, J. L.; Belloni, J.; Delcourt, M. O.; Chevalier, J. P. Nature 397 1985, 317, 344 .

(7) Remita, H.; Khatouri, J.; Treguer, M.; Amblard, J.; Belloni, J. Z. 399 Phys. D 1997, 40, 127.

(8) Treguer, M.; De Cointet, C.; Remita, H.; Khatouri, J.; Amblard, 401 J.; Mostafavi, M.; Belloni, J. J. Phys. Chem. 1998, 102, 4310.

(9) Belloni, J. Curr. Opin. Colloid Interface Sci. 1996, 1, 184.

(10) de Cointet, C.; Khatouri, J.; Mostafavi, M.; Belloni, J. J. Phys. 404 Chem. B 1997, 101, 3517.

(11) Torigoe, K.; Esumi, K. Langmuir 1993, 9, 1664.

12) Michaelis, M. Henglein, A.; Mulvaney, P. J. Phys. Chem. 1994 98,6212

(13) Damle, C.; Kumar, A.; Sastry, M. J. Phys. Chem. B 2002, 106, 409 297.

(14) Turkevich, J.; Kim, G. Science 1970, 169, 873.

(15) Binary Alloy Phase Diagram, 2nd ed; Okamoto, H., Subramanian, 412

R. P., Kacpraz, L., Eds.; ASM International, 1992; Vol. 1.

16) Cardenas, G.; Segura, R Mater. Res. Bull. 2000, 35, 1369.

(17) Baddeley, C. J.; Jefferson, D. A.; Lambert, R. M.; Ormesod, R. 415

M.; Rayment, T.; Schmid, G.; Walker, A. P. Mater. Res. Soc. Symp. Proc 416 1992, 272, 85 .

(18) Toshima, N.; Harada, M.; Yamazaki, Y.; Asakura, K. J. Phys. Chem. 418 1992, 96, 9927.

(19) Liu, H.; Mao, G.; Meng, M. J. Mol. Catal. 1992, 74, 275.

(20) Harada, M.; Asakura, K.; Toshima, N. J. Phys. Chem. 1993, 97, 421 5103

(21) Davis, R.-J.; Boudart, M. J. Phys. Chem. 1994, 98, 5471.

(22) Schmid, G.; Lehnert, A.; Halm, J. O.; Bovin, J. O. Angew. Chem., 424 Int. Ed. Engl. 1991, 30, 874.

(23) Lee, A. F.; Baddeley, C. L.; Hardacre, C.; Ormerod, R. M.; Lambert, R.; Schmid, G.; West, H. J. Phys. Chem. 1995, 99, 6096.

(25) Noshima, N. J. Macromol. Sci-Chem. 1990, A27, 1225.

(26) Mizukoshi, Y.; Okitsu, K.; Yamamoto, T. A.; Maeda, Y.; Nagata, 430 Y. J. Phys. Chem. B 1997, 101, 7033.

(27) Mizukoshi, Y.; Fujimoto, T.; Nagata, Y.; Oshima, R.; Maeda, Y. 432 J. Phys. Chem. B 2000, 104, 6028.

(28) (a) Weaver, J. H.; Benbow, R. L. Phys. Rev. B 1975, 12, 3509. (b) 434

Weaver, J. H.; Krafka, C.; Lynch, D. W.; Koch, E. E. Optical properties of 435 metals; Physics Data Series 18-2; Fachinformationzentrum Karlsruhe, 1981. 436

(29) Gachard, I.; Remita, H.; Khatouri; J.; Keita, B.; Nadjo, L.; Belloni, 437 J. New J. Chem. 1998, 22, 1257 . 